\title{
HIDEYO NOGUCHI Y EL TRACOMA (Inawashiro, Japón, 1876 - Accra, Ghana, 1928)
}

\author{
NOGUERA $\mathrm{JJ}^{1}$
}

\begin{abstract}
Con un recuerdo muy especial para el Prof. D. Diego Díaz Domínguez.

y sus charlas sobre el tracoma.

Navarra, 1972
\end{abstract}

Seisaku Noguchi nació el nueve de noviembre de 1876 en Inawashiro, ciudad de la prefectura japonesa de Fukushima, y en 1897 completó los estudios de medicina en la universidad de Tokio; un año más tarde cambió su nombre por el de Hideyo. En 1900 viajó a los Estados Unidos y allí, después de trabajar entre 1901 y 1903 en la universidad de Pensilvania, fue admitido en el Instituto Rockefeller de Investigación Médica de Nueva York, hoy Universidad Rockefeller, donde, especializado en microbiología, descubrió la etiología de la sífilis al aislar el

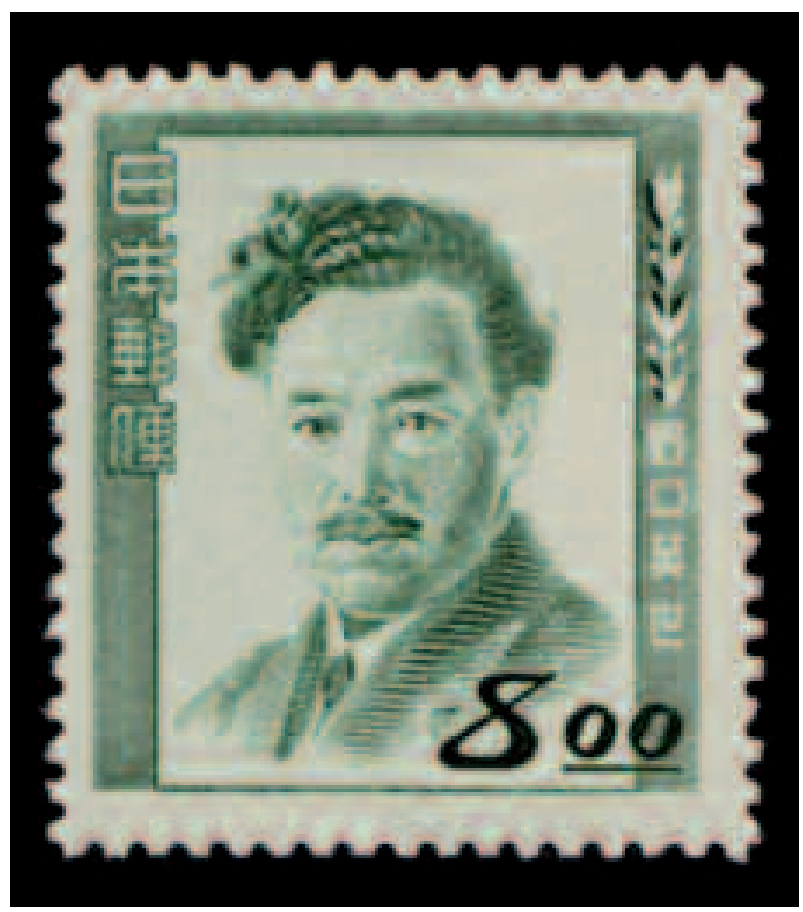

Fig. 1: Japón, 1949 (Yvert 436).
Treponema pallidum en el cerebro y médula espinal de los pacientes fallecidos de esa enfermedad con síntomas neurológicos. Otros de sus campos de investigación fueron la poliomielitis, la rabia, la fiebre de Oroya (enfermedad de Carrión), la fiebre amarilla y las sustancias tóxicas en los venenos de serpientes.

Buena parte de su vida la dedicó al estudio del tracoma, oftalmía egipcia o inflamación granular de los ojos, quizá estimulado por la ceguera que su hermana Inu había adquirido de pequeña tras padecer aquella enfermedad.

Por entonces eran conocidos, entre otros asuntos, los corpúsculos intracelulares descubiertos en 1907 por Stanislau J. M. von Prowazek, zoólogo y microbiólogo austriaco, y Ludwig Halberstädter, radiólogo y dermatólogo alemán, las publicaciones en ese mismo año de R. Greeff, H. Frosch y W. Clausen en las que equiparaban unas diplobacterias encontra-

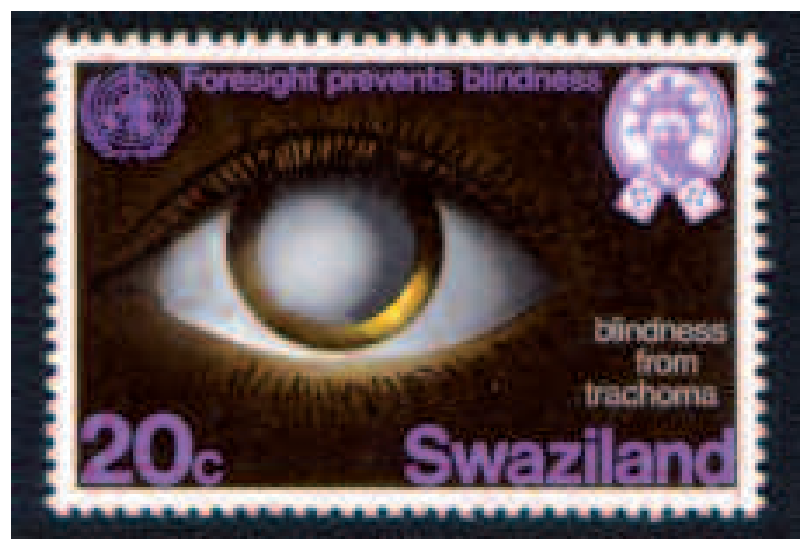

Fig. 2: Suazilandia, 1978 (Yvert 252 de 250/53).

\footnotetext{
1 Oftalmólogo. Pamplona. Navarra. España.

E-mail: jnoguera72b@terra.es
} 
das en muestras tracomatosas con los corpúsculos de Prowazek y Halberstädter, o los denominados cuerpos iniciales descritos en 1921 por el oftalmólogo austriaco Karl Lindner. Pero aún nadie había aislado y cultivado el germen causal del tracoma ni provocado la enfermedad en animales de experimentación.

Noguchi no iba a correr mejor suerte. Trabajando en Albuquerque, Nuevo México (Estados Unidos), inyectó unas muestras de secreción lagrimal de un enfermo de tracoma en la conjuntiva de unos monos y preparó con ellas varias placas de cultivo; al cabo de un tiempo, en los monos apareció una conjuntivitis folicular y en alguno de los cultivos, un bacilo. Este germen aislado se aplicó después en los ojos de otros monos sin que esto tuviera consecuencia alguna. En la reunión de la Asociación Médica Americana de 1927, Noguchi presentó estos resultados y propuso el nombre de Bacterium granulosis para el probable germen causal de tracoma; unos años más tarde se comprobó que la conjuntivitis que producía no era un tracoma sino una simple folicular. El propio Karl Lindner se infectó un ojo con aquel bacilo para demostrar que sólo era un inocuo germen saprofito.

Hideyo Noguchi falleció en Accra (Ghana) el 21 de mayo de 1928 sin conocer la causa del tracoma. Contrajo la fibre amarilla al contagiarse mientras investigaba sobre su etiología.

La filatelia le ha dedicado unos pocos sellos: en Japón, 1949 (Yvert 436), Ecuador, 1977 (Yvert: aéreo 634 + HB 29) y Ghana, 1977 (Yvert 1985/89 + HB 306/07). Para el tracoma, Suazilandia, 1978 (Yvert 250/53) — ¿con una catarata? - y Cuba, 1976 (Yvert 1918) con las inclusiones celulares.

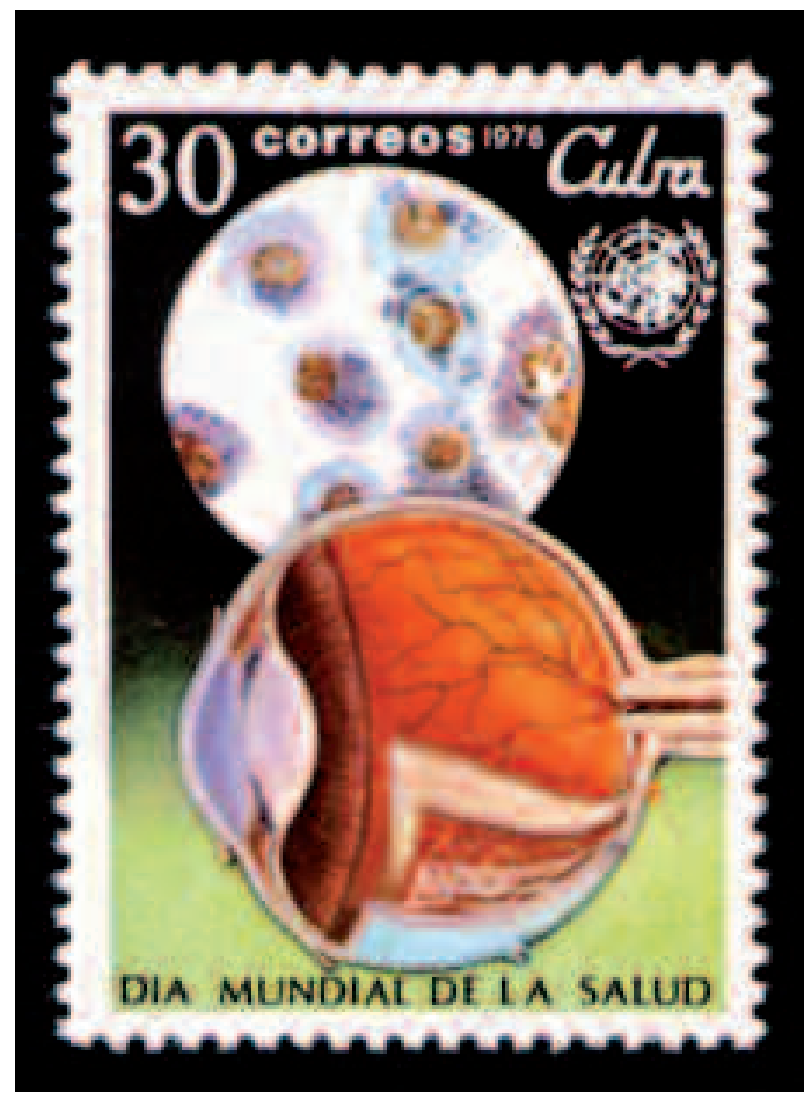

Fig. 3: Cuba, 1976 (Yvert 1918).

\section{NOTAS}

Desde 2004, los billetes japoneses de 1.000 yenes llevan la efigie de H. Noguchi. 